Arch Virol (1993) [Suppl] 7: 75-80

(C) Springer-Verlag 1993

\title{
Toroviruses - members of the coronavirus superfamily?
}

\author{
M.C. Horzinek \\ Divison of Virology, Department of Infectious Diseases and Immunology, \\ Veterinary Faculty, University of Utrecht, Utrecht, The Netherlands
}

\section{Introduction}

During the last twenty years in Utrecht we have focused on the characterization of enveloped positive-stranded RNA viruses, above all on the well-characterized family of coronaviruses, with the mouse hepatitis and feline infectious peritonitis viruses receiving most attention; in addition, less common and not properly classified agents e.g. equine arteritis virus (EAV) and Berne virus (BEV) have been analyzed. It was quite unexpected when nucleotide sequence comparisons suggested that EAV and BEV are phylogenetically related to each other and to coronaviruses; the properties of the latter have been reviewed [16, 17]. The present paper summarizes some data on toroviruses and gives the arguments why these are considered as evolutionarily related with corona- and arteriviruses.

\section{Berne virus - the torovirus prototype}

Berne virus (BEV) has become the prototype of a new taxon in virology [4]. Toroviruses represent a group of enveloped, positive-stranded RNA viruses with a unique and altogether protean morphology. An elongated, bacilliform core with two rounded ends is surrounded by a membrane which may either tightly adhere or "shrink-wrap" it; in the first instance straight or curved rods are formed, in the latter case a biconcave disk results [for reviews see 10,11]. Virion pleomorphism in negatively stained preparation is probably the reason why these ubiquitous viruses have not been discovered earlier; in ultrathin sections, however, the characteristic "hollow" tubular capsids are conspicuous, especially when forming twin circular structures in transversal sections [22].

The history of torovirology is brief - it started with a study on the cause of calf diarrhoea. Breda virus (BRV) was discovered in 1979 
during investigations in a dairy herd in Breda (Iowa), in which severe neonatal calf diarrhea had been a problem for 3 subsequent years. Faecal material was found to contain pleomorphic particles which carried club-shaped projections similar to coronaviruses, but which were antigenically unrelated to them [23]. Despite repeated attempts, BRV had at that time not been adapted to growth in cell or tissue culture which has hampered its biochemical, biophysical and molecular characterization. In the meanwhile, the problem of in-vitro propagation has been solved: respiratory strains of bovine toroviruses were grown with cytopathic effect in Madin-Darby bovine cell culture, and subsequently in a range of other cells from different animal species [19].

Breda virus (BRV) had many properties in common with a chance isolate from a horse presented at the Veterinary School in Berne, Switzerland; the isolation had been made already in 1972, and early characterization of BEV resulted from a collaboration between laboratories at Berne and Utrecht [21]. Toroviruses occur in rodents, carnivores, ungulates and man. Most infections are enteric, but antigen has also been found in respiratory lesions of calves and in aborted bovine fetuses [20].

Toroviruses and coronaviruses are related by divergence of their polymerase and envelope proteins from common ancestors. In addition, their genome organization and expression strategy, which involves the synthesis of a $3^{\prime}$-coterminal nested set of mRNAs, are comparable. Nucleotide sequence analysis of the genome of BEV has revealed the results of two independent non-homologous RNA recombinations during torovirus evolution. Berne virus open reading frame 4 encodes a protein with significant sequence similarity (30-35\% identical residues) to a part of the hemagglutinin esterase proteins of coronaviruses and influenza virus $\mathrm{C}$. The sequence of the $\mathrm{C}$-terminal part of the predicted $\mathrm{BEV}$ polymerase open reading frame 1a product contains $31-36 \%$ identical amino acids when compared with the sequence of a non-structural $30 /$ $32 \mathrm{~K}$ coronavirus protein. The cluster of coronaviruses which contains this non-structural gene does not express it as a part of their polymerase, but by synthesizing an additional subgenomic mRNA [14, 15].

\section{Arteriviruses}

Another virus which has occupied my groups in Tübingen and Utrecht is EAV. As a result of early attempts at characterization, it became the prototype of the genus arterivirus in the family Togaviridae, with lactic dehydrogenase virus (LDV) as another possible member [4]. The 
spherical enveloped arterivirion has a diameter of 50-70 nm and contains an isometric, probably icosahedral nucleocapsid $35 \mathrm{~nm}$ in diameter, as determined for EAV [8] and LDV [6]. The envelope carries ring-like surface structures - no peplomeric subunits like coronaviruses [7]. The similarity in molecular weights of the structural proteins was another trait that motivated their grouping in one cluster ("lactiviruses": [6]). The genome is a single positive-stranded RNA molecule, less than half the size of coronaviral genomes, which contains multiple ORFs. During EAV replication again a 3'-coterminal nested set of subgenomic RNAs appears. They are composed of leader and body sequences which are not contiguous on the EAV genome and perhaps are formed by alternative splicing. The leader sequence is derived from the extreme $5^{\prime}$ end of the EAV genome [2]. Leader sequences are also present in coronaviruses, but have not been found in toroviruses.

We have recently shown that the EAV genome contains seven open reading frames (ORFs) and presented data on the structural proteins and the assignment of their respective genes. Virions are composed of a $14 \mathrm{kDa}$ nucleocapsid protein $(\mathrm{N})$ and 3 membrane proteins designated $M, G_{S}$, and $G_{L} . M$ is an unglycosylated protein of $16 \mathrm{kDa}, G_{S}$ and $\mathrm{G}_{\mathrm{L}}$ are N-glycosylated proteins of $25 \mathrm{kDa}$ and $30-42 \mathrm{kDa}$, respectively. Using monospecific antisera and expression of individual ORFs, the genes for the structural proteins were identified: ORF 7 codes for $\mathrm{N}$, ORF 6 for M, ORF 5 for $G_{L}$, and ORF 2 for $G_{S}$. With the exception of $\mathrm{G}_{\mathrm{S}}$, the proteins are about equally abundant in EAV virions, being present at a molar ratio of $3(\mathrm{~N}): 2(\mathrm{M}): 3\left(\mathrm{G}_{\mathrm{L}}\right)$. The $\mathrm{G}_{\mathrm{S}}$ protein which is expressed at a level similar to that of $\mathrm{M}$ in infected cells, is strikingly under-represented $(1-2 \%)$ in virus particles [3].

Study of arteriviruses at the molecular level has received a boost during the last two years, and genomic properties similar to those described above were identified for LDV [12] and Lelystad virus (LV), the cause of "mystery swine disease" or swine infertility and respiratory syndrome. A sequence of 15,088 nucleotides with eight ORFs was determined; ORFs $1 \mathrm{a}$ and $1 \mathrm{~b}$ contain sequence elements that are conserved in the RNA polymerase genes of BEV, EAV and LDV, coronaviruses and of other positive-stranded RNA viruses [13]. We had shown before that in corona- and toroviruses the polymerase is translated from ORF1 by a process of ribosomal frame-shifting, for which a pseudoknot and a preceding "slippery" nucleotide sequence are preconditions $[1,14]$; the same arrangement has now been found also for LV. Comparison of the amino acid sequences has indicated that $\mathrm{LV}$ is more closely related to LDV than to EAV [13]. The genome of Simian Haemorrhagic Fever virus, a fourth representative of this cluster, is presently being sequenced (Brian Mahy 1992, pers. comm.). 


\section{The "superfamily" concept}

During the last decade, various "replicase modules" have been recognized among positive-stranded RNA viruses. They form the basis for "superfamilies" of plant and animal viruses, the two largest of which are those of the picornavirus- and alphavirus-like "superfamilies" [18]. More recently, we have proposed a third "superfamily" [17] which would comprise the corona-, toro- and arteriviruses. The importance of at least three conserved domains in corona- and toroviral polymerases [14] is underlined by their presence in the putative polymerase of the only distantly related EAV. Two domains are believed to possess polymerase and helicase activities and are common in positive-stranded RNA viruses. However, the conservation, both in sequence and in relative position, of a third domain suggests that it also plays a role in viral replication - a hypothesis supported by the fact that it also occurs in the putative polymerase of LDV. It is tempting to speculate that this domain performs a function which is specific for this cluster of viruses, e.g. the synthesis of multiple subgenomic mRNAs.

On the basis of the similarities in polymerase expression and amino acid sequence we postulate that the polymerase genes of arteri-, coronaand toroviruses have descended from a common ancestor. In contrast to the helical nucleocapsid structure of corona- and toroviruses, the nucleocapsids of EAV, like those of togaviruses, possess an isometric, probably icosahedral architecture. Also, the EAV envelope does not bear elongated peplomers. The coupling of different sets of structural genes to the same replicase has been explained by recombination of complete genes or gene sets (modules). Together with divergence from a common ancestor, this modular evolution can account for the diverse composition of viral genomes [18]. In arteriviruses, the coupling of a coronavirus-like replicase module to a set of structural genes - which confer togaviral morphology to the virion - might be another example of modular evolution.

\section{Concluding remarks}

There is another line of evolution that should be mentioned here: that of viral taxonomy. While virion details have dominated classification in the early days, genome organization and replication strategy are now en vogue. Indeed the traits shared between corona- and toroviruses have resulted in their classification as genera of the family Coronaviridae, as agreed upon at the interim meeting of the ICTV (Oxford, April 1992). However, taxonomy should not only be intellectually appealing but 
also practical, and structural features must not be abolished altogether. Lumping divergent viruses together in families only because their replication contains similar elements does a disservice to the community of virologists at large, which includes teachers and diagnosticians. Arteriviruses are structurally unrelated to the Coronaviridae and should be given separate status - a feeling unanimously expressed during the 5th International Coronavirus Symposium (Chantilly, September 1992). The hierarchical category of the order would be appropriate to replace the unofficial category of "superfamily".

\section{Acknowledgements}

The author should like to thank Miss Janneke Meulenberg, Central Veterinary Institute Lelystad, and Dr. E.Vanopdenbosch, The National Institute for Veterinary Research Brussels, for sharing unpublished information. My former collaborators Willy Spaan, Eric Snijder, Johan den Boon (Leiden, The Netherlands) and Marion Koopmans (Atlanta, USA) have contributed most of the original data reviewed above, and their continued effort and interest is gratefully acknowledged.

\section{References}

1. Bredenbeek PJ, Pachuk CJ, Noten JFH, Charité J, Luytjes W, Weiss SR, Spaan WJM (1990) The primary structure and expression of the second open reading frame of the polymerase gene of coronavirus MHV-A59. Nucleic Acids Res 18: $1825-1832$

2. de Vries AAF, Chirnside ED, Bredenbeek PJ, Gravestein LA, Horzinek MC, Spaan WJM (1990) All subgenomic mRNAs of equine arteritis virus contain a common leader sequence. Nucleic Acids Res 18: 3241-3247

3. de Vries AAF, Chirnside ED, Horzinek MC, Rottier PJM (1992) The structural proteins of equine arteritis virus. J Virol 66: 6294-6303

4. Francki RIB, Fauquet CM, Knudson DL, Brown F (1991) Classification and nomenclature of viruses. 5th Report of the International Committee on Taxonary of Viruses. Springer, Wien New York (Arch Virol [Suppl] 2)

5. Godeny EK, Speicher DW, Brinton MA (1990) Map location of lactate dehydrogenase-elevating virus (LDV) capsid protein (Vp1) gene. Virology 177: 768-771

6. Horzinek MC (1975) The structure of togaviruses and bunyaviruses. Med Biol 53: 406-411

7. Horzinek MC (1981) Non-arthropod-borne togaviruses. Academic Press, London

8. Horzinek M, Maess J, Laufs R (1971) Studies on the substructure of togaviruses. II. Analysis of equine arteritis, rubella, bovine viral diarrhoea, and hog cholera viruses. Arch Ges Virusforsch 33: 306-318

9. Horzinek MC, Van Wielink PS, Ellens DJ (1975) Purification and electron microscopy of lactic dehydrogenase virus of mice. J Gen Virol 26: 217-226

10. Horzinek MC, Flewett TH, Saif LF, Spaan WJM, Weiss M, Woode GN (1987a) A new family of vertebrate viruses: Toroviridae. Intervirology 27: 17-24 
11. Horzinek MC, Weiss M, Ederveen J (1987b) Toroviridae: a proposed new family of enveloped RNA viruses. In: Bock G, Whelan J (eds) Novel diarrhoea viruses. CIBA Foundation Symp 128. Wiley, Chichester, pp 162-174

12. Kuo L, Chen Z, Rowland RRR, Faaberg KS, Plagemann PGW (1992) Lactate dehydrogenase-elevating virus (LDV): subgenomic mRNAs, mRNA leader and comparison of 3'-terminal sequences of two LDV isolates. Virus Res 23: 55-72

13. Meulenberg JJM, Hulst MM, de Meijer EJ, Moonen PLJM, den Besten A, de Kluyver EP, Wensfoort G, Moorman RJM (1992) Lelystad virus, the causative agent of porcine epidemic abortion and respiratory syndrome (PEARS), is related to LDV and EAV. Virology 192: 62-72

14. Snijder EJ, den Boon JA, Bredenbeek PJ, Horzinek MC, Rijnbrand R, Spaan WJM (1990) The carboxy-terminal part of the putative Berne virus polymerase is expressed by ribosomal frameshifting and contains sequence motifs which indicate that toro- and coronaviruses are evolutionarily related. Nucleic Acids Res 18: $4535-4542$

15. Snijder EJ, den Boon JA, Horzinek MC, Spaan WJM (1991) Comparison of the genome organization of toro- and coronaviruses: evidence for two non-homologous recombination events during Berne virus evolution. Virology 180: 448-452

16. Spaan W, Cavanagh D, Horzinek MC (1988) Coronaviruses: structure and genome expression. J Gen Virol 69: 2939-2952

17. Spaan W, Cavanagh D, Horzinek MC (1990) Coronaviruses. In: van Regenmortel MHV, Neurath AR (eds) Immunochemistry of viruses, vol 2. The basis for serodiagnosis and vaccines. Elsevier Science Publishers, Amsterdam, pp 359-375

18. Strauss JH, Strauss EG (1988) Evolution of RNA viruses. Annu Rev Microbiol 42: $657-683$

19. Vanopdenbosch E, Wellemans G, Charlier G, Petroff K (1992a) Bovine torovirus: cell culture propagation of a respiratory isolate and some epidemiological data. Valams Tijschr Diergeneesk 61: 45-49

20. Vanopdenbosch E, Wellemans G, Oudewater J, Petroff K (1992b) Prevalence of torovirus infections in Belgian cattle and their role in respiratory, digestive and reproductive disorders. Vlaams Tijschr Diergeneesk 61: 187-191

21. Weiss M, Steck F, Horzinek MC (1983) Purification and partial characterization of a new enveloped RNA virus (Berne virus). J Gen Virol 64: 1849-1858

22. Weiss M, Horzinek MC (1987) The proposed family Toroviridae: agents of enteric infections. Arch Virol 92: 1-15

23. Woode GN, Reed DE, Runnels PL, Herrig MA, Hill HT (1982) Studies with an unclassified virus isolated from diarrhoeal calves. Vet Microbiol 7: 221-240

Author's address: Dr. M.C. Horzinek, Division of Virology, Dept. Infectious Diseases and Immunology, Veterinary Faculty, University of Utrecht, P.O. Box 80.165, Yalelaan 1, 3508 TD Utrecht, The Netherlands. 